\title{
EXPRESIÓN DE LA OPTATIVIDAD Y MODO SUBJUNTIVO EN EL HABLA CULTA COSTARRICENSE
}

\author{
Jorge Murillo M.
}

\begin{abstract}
RESUMEN
Este artículo describe cómo se expresa, en el español culto costarricense, la noción de optatividad usando el presente de subjuntivo. Sigue, en general, los lineamientos para el estudio del habla culta propuestos en el "Proyecto de estudio coordinado de la norma linguística culta de las principales ciudades de Iberoamérica y de la Península Ibérica".
\end{abstract}

\begin{abstract}
The article describes how is expressed the notion of optativity, using the subjuntive mood, in Costa Rican educated Spanish. It also follows the general guidelines proposed for the "Proyecto de estudio coordinado de la norma lingüística culta de las principales ciudades de Iberoamérica y de la Península Ibérica".
\end{abstract}

No es un secreto que las hablas centroamericanas han sido poco estudiadas (sino olvidadas o consideradas como bloque lingüístico unitario). En Costa Rica, sin embargo, se ha despertado en la última década un interés creciente por el estudio del habla culta, con miras a integrarnos dentro de este vasto proyecto que se lleva a cabo en las principales ciudades hispanohablantes (Proyecto de estudio coordinado de la norma lingüística culta de las principales ciudades de Iberoamérica y de la Península Ibérica) y cuyo gestor fue el Dr. Lope Blanch, en 1964.

El siguiente estudio es una muestra de ese interés suscitado por el proyecto en el ámbito costarricense y se delimita al estudio de la expresión de la optatividad por medio del presente de subjuntivo. En esencia, se propone una descripción de las diferentes maneras en que los hablantes expresan la noción semántica de optatividad usando este modo.

Se trabajó con 36 entrevistas (20 horas de grabación, con 32 entrevistas de media hora cada una y 4 de 45 minutos) en las cuales participan 46 informantes, divididos de la siguiente forma: 10 informantes de la I generación (de entre 25 y 35 años, que correspoden al 21.75\%); 21 de la II generación (de entre 36 y 55 años, para un total de $45.65 \%$ ) y 15 de la tercera (mayores de 55 años, un $32.60 \%$ ). Del total de informantes, $50 \%$ son mujeres y $50 \%$, hombres ${ }^{1}$.

Los informantes son de la zona metropolitana (San José), por cuanto ésta es el foco de irradiación cultural del país. Todos los informantes tienen educación superior; en su mayoría son egresados o estaban en los últimos años de estudio. Se seleccionaron atendiendo a los siguientes factores socioculturales: ambiente familiar, grado de instrucción (incluyendo lecturas, viajes y dominio de lenguas extranjeras), ocupación. Además, se consideró que fueran nacidos en el área metropolitana o al menos que hubieran residido en esta zona durante 
tres cuartas partes de su vida. Debían ser hijos de hispanohablantes, preferentemente nacidos en la misma ciudad y también debían haber recibido toda su instrucción formal —incluyendo la superior - en la misma ciudad.

Se parte del supuesto de que la optatividad se asocia al uso del subjuntivo en aquellos casos en que se exprese deseo o exhortación. El llamado subjuntivo optativo incluiría una variedad de enunciados que irían desde la expresión de un deseo del hablante, pasando por la exhortación atenuada, hasta llegar a aquellos casos en que se ordena o manda, en forma directa, hacer algo.

La gramática tradicional ha establecido una categorización diferenciada entre los enunciados que expresan deseo y los que expresan mandato. Para los primeros, se emplearía el subjuntivo, acompañado de expresiones como ojalá; para los segundos, se utilizarían las formas correspondientes al imperativo, concebido como modo diferenciado del subjuntivo. La Real Academia señala que estas formas verbales manifiestan la función apelativa del lenguaje y que este modo solo tiene dos formas verbales: las de segunda persona singular. Como característica sintáctica definitoria de este modo, señalan el hecho de que no puede aparecer en construcción subordinada, además de que, en el caso de las formas negativas, se emplearía el presente de subjuntivo.

Alarcos (1970), por otra parte, lo hace aparecer como fuera del sistema de representación verbal que él propone, aduciendo que pertenece a un plano especial de la lengua: "...el imperativo, que ordena o exhorta y se dirige a alguien, debe considerarse fuera del sistema del plano de la "Darstellung" y solo perteneciente al plano de la "Appell" o llamada al interlocutor." (61) Corrobora esta afirmación apoyándose en rasgos morfológicos y sintácticos: solo admite los pronombres en posición enclítica y no usa la -s para la segunda singular; en su lugar, utiliza un formante único dentro del sistema verbal: -d.

Siguiendo esta misma línea de interpretación está el estudio de Lamíquez (1982), quien separa al imperativo, como modo, del resto del sistema verbal, aduciendo, con Alarcos, "...que el imperativo es para oraciones con modalidad exhortativa y queda fuera de la "dimensión modal" del verbo español" (46).

No obstante, aún dentro de estas aproximaciones, ha existido siempre la duda de si en realidad estas oraciones deben considerarse como constructos no relacionados. Así puede apreciarse ya en las consideraciones de Bello, para quien el imperativo constituía una modalidad del optativo (§ 220):

La formas optativas reciben una inflexión especial, cuando la persona a quien hablamos es la que debe cumplir el deseo, y lo que se desea se supone depender de su voluntad, y se expresa por una preposición que no contiene palabra negativa. Diga, por ejemplo, pasa entonces a di, y sea a sé.

Las formas verbales de las cuales partían estos gramáticos reseñados (a modo de ejemplo), eran siempre aquellas correspondientes a la forma directamente heredada del latín para tal función y usadas en la actualidad en el español peninsular. Sin embargo, las intrusiones del subjuntivo dentro del llamado modo imperativo en el español americano van más allá de utilizarse en las formas negativas. Las formas con morfema $-d$ se desconocen dado que no se utiliza el vosotros; en las zonas tuteantes, se emplean las mismas variantes peninsulares; en las voseantes, se utiliza la forma especial, carente de morfema específico (comé o salí, por 
ejemplo), para la expresión de cualquier mandato u orden. De esta manera, pues, en estas últimas áreas se han perdido totalmente todas las formas originarias de imperativo y, en general, el subjuntivo se usa para expresar tal función. Por esta razón, cualquier estudio - como el nuestro- que analice las formas de presente de subjuntivo, tiene que incluir forzosamente aquellos usos en que la modalidad de enunciación sea meramente apelativa.

De hecho, el partir de la concepción de modalidad $^{2}$ nos facilita el análisis de estas formas como parte del subjuntivo optativo, como lo había propuesto Bello y como lo defiende César Hernández, amparándose en criterios semánticos y pragmáticos:

\begin{abstract}
Del deseo arrancan una serie de variantes semánticas, todas ellas marcadas por el rasgo [+volición], que son el ruego, el mandato y la concesión. Las diferencias entre éstas son claras: mandato, consejo, ruego y concesión, además, responden a la función conativa, están marcados por una obligada intercomunicación, que condiciona sus formas de expresión, mientras que el deseo es la plasmación de la función expresiva, con el sema volitivo (1995: 50).
\end{abstract}

Es evidente, entonces, que las formas de imperativo, máxime cuando se trata de las de subjuntivo en tal función, están emparentadas desde la perspectiva de la modalidad del enunciado: ambas corresponden a la dimensión de lo volitivo; se pueden diferenciar, empero, en su modalidad de enunciación, ya que mientras que el tradicionalmente llamado subjuntivo optativo se ubica dentro de la esfera de lo declarativo, las de orden o mandato lo hacen dentro de la modalidad exhortativa.

Las diferencias desde el punto de vista sintáctico entre unas y otras, si las hay, habría que establecerlas basándose en el examen de un corpus determinado, lo cual permitiría, a su vez, proponer una nueva perspectiva de análisis ${ }^{3}$.

Entre las formas de subjuntivo exhortativo, encontramos en nuestro corpus los siguientes casos:

\title{
1. Formas de subjuntivo optativo: modalidad desiderativa
}

Se agruparían aquí aquellas oraciones que expresan una modalidad de enunciación declarativa (tradicionalmente subjuntivo optativo), en que la intención del hablante no va más allá de expresar una volición sin que necesariamente ello implique la ejecución de acto alguno por parte del interlocutor. De este tipo, sorprendentemente, solo aparecieron tres casos en presente de subjuntivo, dos con la marca tradicional para tal función, el adverbio ojalá, y otra sin modificador alguno.

(1) Sí, ojalá pueda de veras ir a ver las fies... las piedras de Agronomía antes de que se vaya...

(2) ¡Vivan las diferencias!, decían allá en las Cortes de Cádiz.

A pesar de que el ejemplo (1) responde a la modalidad de enunciación declarativa, es evidente que en ella existen visos de cierta función conativa, en tanto el verbo está en segunda persona singular y el informante modaliza la frase como un medio para expresar un deseo 
propio que se vería cumplido si el interlocutor acepta su idea. En el caso (2), el informante cita una frase acuñada en su acervo cultural, como recurso de apoyo para lo que afirma.

La frecuencia tan baja de aparición de enunciados desiderativos puede justificarse por las circunstancias de comunicación al llevar a cabo las encuestas, pues no existieron los contextos propicios para la utilización de formas optativas que, en el uso general, están relegadas a planos muy propios de relaciones de amistad o parentesco bastante íntimas. Desde un punto de vista sintáctico, las frases que contienen la expresión ojalá, por otra parte, no presentan mayor variedad en cuanto al uso de modo, pues solo admiten el subjuntivo.

El otro caso que ubicamos dentro de este aparte corresponde a una construcción fija de la lengua, por lo menos en los dialectos costarricenses:

(3) Inf.: Entonces te llegan las cosas más terribles (se refiere a los estudiantes): te llegan tontitos, así, más bien...

$$
\text { Enc.: ¿Chusma? }
$$

Inf.: Ni se diga chusma.

Con esta expresión (ni se diga) el hablante manifiesta su deseo de que algún evento o persona que resulta molesto para él no sea mencionado, aunque también, como recurso irónico, la frase sirve para graduar el sustantivo, adjetivo o verbo en cuanto a su intensidad o frecuencia; en este caso específico, el informante expresa su aversión para con la chusma, y a la vez deja bien claro que esa antipatía proviene de la cantidad excesiva de chusma con la que tiene que tratar.

\section{Formas de subjuntivo optativo: modalidad yusiva}

En esta categoría se agrupan los casos en que claramente se establece una intención yusiva por parte del hablante, en tanto existe un interlocutor al que él se dirige para expresarle su ruego, mandato o consejo.

Para la interpretación de los datos, se tomó en cuenta el grado de yusividad y la persona gramatical de las formas: casos en que se enuncia una exhortación atenuada (formas en primera persona plural) y aquellos en que el mandato o consejo es más directo (con formas en segunda persona singular o plural). Ha de hacerse la salvedad, por otra parte, de que en la mayoría de usos de segunda persona las frases aparecen en discurso directo, por lo cual el sujeto de la enunciación no corresponde necesariamente con el sujeto del enunciado.

Dentro del primer grupo tenemos, pues, las clásulas con formas en primera persona plural, en las cuales se da una línea poco demarcada entre lo que sería lo propiamente desiderativo, como modalidad declarativa, y lo yusivo, ya que el sujeto de la enunciación expresa un deseo, en el que va incluido él y por medio del cual, por otra parte, pretende incitar al oyente a que participe de sus intenciones.

A este tipo de construcciones se les ha etiquetado, dentro de los estudios lingüísticos ${ }^{4}$, como subjuntivo exhortativo, pues el hablante también participa de la acción que él mismo ordena ejecutar a los otros. Concretamos más la clasificación con la denominación de inclusivas 
(que diferenciaremos más abajo de las exclusivas) pues el hablante se hace partícipe de la acción que él mismo propone.

Se contabilizaron 7 casos $(9.72 \%)$, de entre los cuales transcribimos, a manera de ejemplo, los siguientes:

(4) Hablemos de cosas bonitas

(5) Véamolo positivo

(6) Sí, mañana se verá a ver qué se hace y hagámoslo hoy.

(7) Pensemos en el Colegio Superior de Señoritas, al que quizá incluso sería interesante dedicar una de estas sesiones,...

La marcada tendencia a expresar un deseo del cual se haga partícipe al interlocutor es evidente en los tres primeros casos. En ellos, como decíamos, es difícil demarcar una división clara entre lo puramente desiderativo y lo exhortativo, en vista de que el sujeto de la enunciación es singular (el informante) mientras que el del enunciado es plural (informante e interlocutor), es decir, el yo y el tú se aúnan, en la esfera del deseo, en una sola representación lingüística.

El caso (7) difiere un tanto de los otros dos, en vista de que aquí se da una llamada directa al interlocutor para que piense o imagine algo que el informante tiene en mente, en un deseo de establecer un marco común de referencia para el tema que está tratando. Hay dos funciones del lenguaje trabadas en tal enunciado: la puramente exhortativa y la referencial, en tanto el deseo del hablante es remitirse a un referente específico, que él supone conocido por su interlocutor. Con este mismo sentido, hay otros dos enunciados, uno en segunda persona singular y otro en segunda plural.

Hay dos casos más que interesan desde el punto de vista de la variación modal:

(8) El error es de ellas tres. Vamos a hablar con Mayra al Ministerio.

(9) Y (el profesor) nos dio un poquito de Física... apenas... cualquier cosita y ya vámonos.

La concurrencia de indicativo y subjuntivo en este tipo de construcciones con el verbo ir es frecuente en los distintos dialectos del español. Según Kany (1969), debido a que tanto vamos como vayamos tienen el mismo étimo latino, en la antigüedad ambas formas se podían emplear como tales, especialmente en sentido imperativo. Apunta que "En la actualidad, el habla consagrada limita generalmente a vamos el sentido optativo, reservando vayamos para los demás usos del subjuntivo" (215).

A juzgar por estos dos únicos casos de aparición dentro del total de datos, no se podría establecer si existen otros contextos donde los hablantes prefieran usar la forma propiamente subjuntiva en construcciones exhortativas inclusivas. Sí hay que destacar que, de acuerdo con nuestras observaciones generales sobre el habla culta costarricense, la forma más común es aquella con indicativo, tanto en perífrasis $(i r+a+$ infinitivo $)$ como en formas simples. 
El segundo subgrupo de formas pertenecen a un uso que denominamos como exhortativas exclusivas, pues en estas cláusulas se parte del presupuesto de que el hablante debería ser partícipe de la acción, pero se excluye voluntariamente y se exime de responsabilidad alguna. Transcribimos 3 de los 4 casos $(5.56 \%)$ encontrados:

(10) Sí, en cualquier momento (me suicido), no se preocupen, en cualquier momento, ya no quiero vivir." Y de un pronto lo hizo.

(11) Por ejemplo, para un forestal es muy sencillo... puede ser más fácil decir: "Bueno, corten ese montón de árboles y hagan un plan de manejo."

(12) Yo dije que, como es un... yo me limpio las manos, no tengo nada que ver con esto, arréglense, busquen quién.

En (10), es evidente que el sujeto de la enunciación, aún cuando esta oración corresponda a una cita en estilo directo, desea liberarse de cierta responsabilidad que más bien descarga en su(s) interlocutor(es). En estos casos, para entender la plenitud semántica de la exhortación, no podemos confiarnos solamente del verbo sino que hay que tomar en cuenta la relación que se establece entre hablante-oyente y analizar además el contexto semántico de la frase, pues hay otros elementos que refuerzan este rasgo de responsabilidad/participación por parte del hablante: adverbios de negación, sintagmas coloquiales casi lexicalizados como me limpio las manos o es muy sencillo decir... y, en el nivel suprasegmental, probablemente la entonación sea la mejor clave para descifrar este sentido.

Al tercer subgrupo de formas las denominamos propiamente imperativas, porque corresponden a lo que, en la tradición, se entienden como órdenes dirigidas al interlocutor para que este realice determinada acción, es decir, que el hablante espera una acción determinada como respuesta a su ilocución. Estas formas se comportan, sintáctica y semánticamente, de la misma manera en que lo hacen aquellas a las cuales la gramática reconoce la función propiamente imperativa, a saber, ama, amad. Como ya se ha establecido, el hecho de que en el español de Costa Rica no se emplee el tú y, como en el resto de América, se desconozca el vosotros, ha resultado en un mayor uso del subjuntivo para las expresiones de carácter imperativo.

En cuanto a la noción de imperatividad que manejamos, debe aclararse que responde, grosso modo, a la defendida por Studerus (1975), para quien, una orden consiste en "The oral conveyance of one speaker's will concerning some response, made directly to an adressee whom the speaker deems capable of responding — actively or passively — subsequent to being addressed." De acuerdo con este principio, las frases que tienen propiamente carácter imperativo se diferenciarían de las anteriores, en cuanto se espera una respuesta de la persona interpelada, la cual no necesariamente debe ser ejecutada en el momento mismo del acto de enunciación. Lo que juega un papel importante aquí es la intención del hablante, en cuanto para él el acto-respuesta del oyente es posible de llevar a cabo, aunque no como una obligación absoluta, pues eso depende de la voluntad del interlocutor.

Se contabilizaron 46 formas $(63.89 \%)$ que responden a los criterios descritos. Analizamos en seguida sus rasgos más relevantes, agrupándolas con base en rasgos semánticos y sintácticos comunes. 
Los enunciados pueden subdividirse también de acuerdo con la situación comunicativa: aquellos en los que el sujeto de la enunciación es el mismo del enunciado y aquellos en que no. Se esperaría que los primeros se citaran en forma directa o en discurso referido y los segundos no, pero en general (excepto en dos casos) todos los ejemplos son referidos como parte de una experiencia comunicativa anterior al momento de la entrevista, por lo tanto, se usa la transposición discursiva como mecanismo sintáctico de construcción de las frases.

Debe aclararse, por otra parte, que se obvia la subordinación indirecta que podría plantearse para todos estos casos de discurso directo o indirecto, más que todo por facilitar los principios de presentación y análisis de los enunciados y debido a que todas estas oraciones imperativas no presentan la misma relación de dependencia sintáctica que aquellas en las que existe un transpositor o complementador ${ }^{5}$.

Dentro del grupo en que el sujeto de la enunciación es distinto al del enunciado imperativo, algunos ejemplos son:

(13) Y me dice: "No se meta en eso. Eso no (risas). Eso no le produce nada. Métase a estudiar cualquier cosa".

(14) Un día que yo estuve enferma ella me dijo: "No, no, váyase para la casa".

(15) Claro que cuando iban a empezar algún tema prohibido. ¡Ah, no, no! Mamita, vaya...vaya orine. Vaya a tal cosa, vaya....

(16) Entonces hable con el abogado fulano de tal.

Como se puede deducir de los pocos casos transcritos, estas oraciones cumplen plenamente con los rasgos sintácticos que los gramáticos reconocen a todas las frases imperativas:

a. el sujeto normalmente se elide y si aparece va pospuesto. No hay casos de sujeto pospuesto y los casos de elisión son lógicos pues la situación de habla no requeriría de la expresión del sujeto a menos que sea en caso enfático. En (15) aparece un vocativo, mamita, que semánticamente es el mismo sujeto gramatical de la frase, usted, pero este procedimiento es parte de los recursos gramaticales que usa la informante para hacer una recreación más real de la situación a la que se refiere.

b. cualquier pronombre debe preceder al verbo en construcciones negativas y posponérsele en las afirmativas, lo cual se puede corroborar tomando solo el caso (13) donde el mismo verbo aparece en ambos tipos de construcciones con diferente posición del pronombre.

En (15) se presenta un rasgo sintáctico digno de mención pues es característico del español hablado en Costa Rica: la forma vaya ha establecido una relación tan estrecha con las otras formas verbales que se le coordinan en construcción imperativa, haciendo desaparecer la cópula (y) para entrabarse en relación de yuxtaposición: vaya $+y+$ orine $>$ vaya orine. La nueva forma así surgida parece comportarse como perífrasis verbal, dado que ir pierde parcialmente su significación y, por otra parte, es perfectamente sustituible por una forma perifrástica regular: Mamita, vaya orine = Mamita, vaya $a$ orinar . 
En los casos en que el sujeto de la enunciación es el mismo que el del enunciado imperativo, normalmente se encuentra también en transposición directa, como en el ejemplo (17). Solo se dio un caso en que el mandato se dirige al encuestador (18), que además ejemplifica el imperativo con formas voseantes.

(17) Yo, mientras estuve de directora, yo les dije: "Enseñen la ortografía como siempre la hemos enseñado".

(18) No digás nada porque yo no quiero que me hagan nada..... no jodás.

Al último subgrupo de oraciones de modalidad yusiva, lo denominamos yusivas conativas (15 ocurrencias, un $20.83 \%$ ), ya que en ellas la forma verbal funciona como una interpelación directa al hablante para que mantenga el contacto comunicativo en los términos de referencialidad que el informante desea. Los tres verbos que con más frecuencia se emplean en este tipo de construcciones son mirar ( 6 casos), ver (6 casos) y, en menor grado, fijarse, figurarse y suponerse. César Hernández (1995) considera que, en estos casos, las formas verbales se han lexicalizado y "sirven tanto para llamar la atención del interlocutor, como para establecer una pausa a modo de comodín" (52). Transcribimos algunos casos:

(19) Sí, yo ya estoy pensionada pero vea entonces cómo son las vueltas de la vida.

(20) Pero vea usted, muchos colegios de esos privados ya acataron la disposición.

(21) Mire, todo se puede poner a funcionar.

(22) ¡Ay!, es que fíjese que con que se comuniquen de una manera eficaz es bastante.

(23) Y entonces figúrese que yo lo que hacía era coger los chiquitos de segundo y tercero que no sabían leer ni escribir y comenzar a enseñarles.

El rasgo sintáctico que los diferencia de la formas imperativas anteriores es su funcionamiento pleno como verbos independientes y, aún más, su capacidad de aparecer como verbos principales subordinando a otros. En lo semántico, se puede apreciar cómo estos verbos han perdido su significado base para convertirse en meros soportes discursivos o llamadas de atención al oyente, tanto es así que ellos son perfectamente intercambiables sin perjuicio de variación semántica para la totalidad de la frase. Por ejemplo, en (20) se pueden permutar de la siguiente forma:

Pero $\{$ vea $\}$ usted, muchos de esos colegios...

mire

fíjese

figúrese 
Su funcionamiento en el contexto comunicativo es de suma importancia para el hablante ya que le aseguran el mantener el contacto con el oyente. Así, la función dominante en estas construcciones sería la conativa.

A modo de conclusión, presentamos un cuadro con las diferentes ramificaciones de las modalidades optativas y sus respectivos ejemplos tomados del corpus.

\section{Resumen}

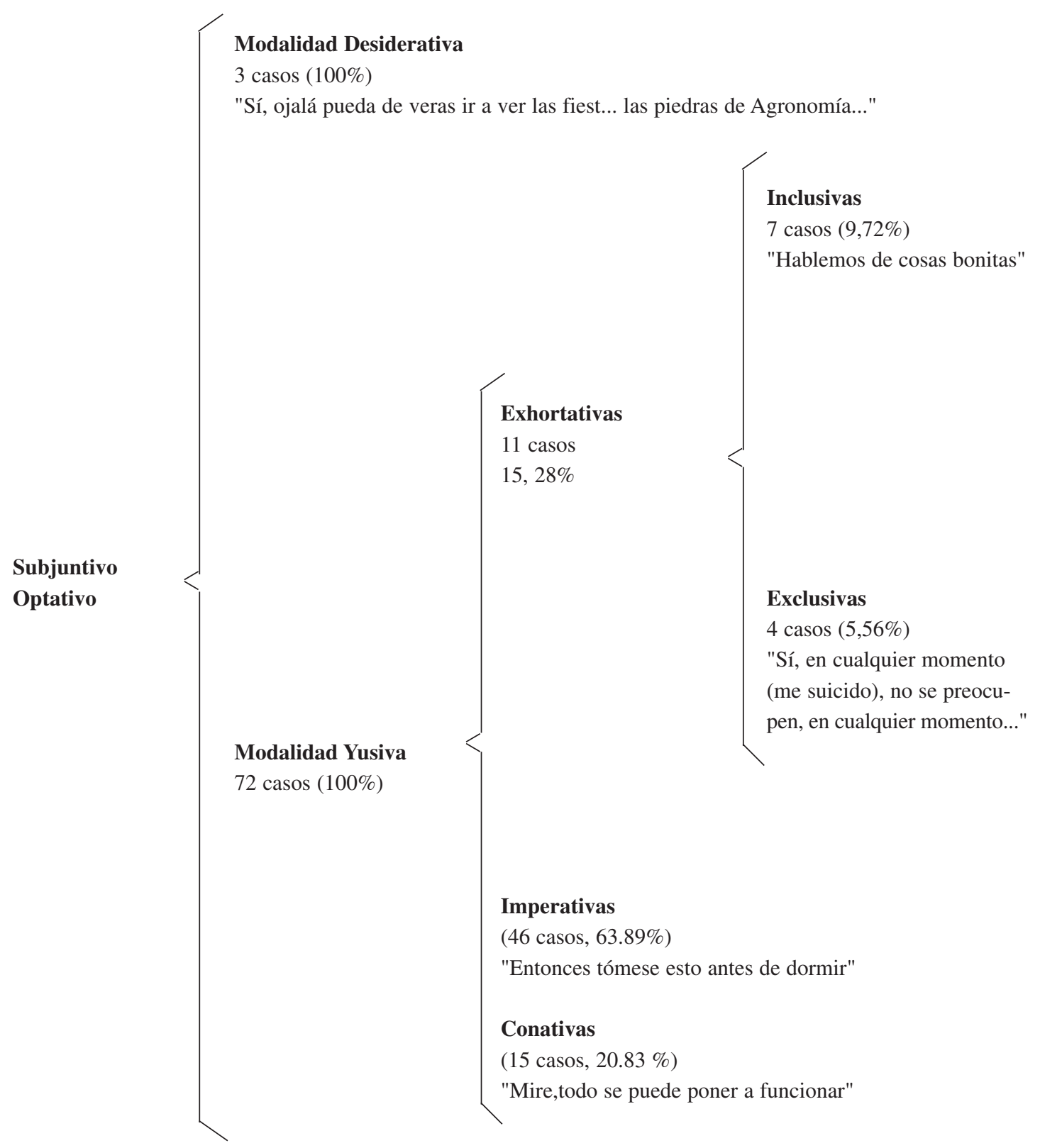




\section{Notas}

1. Los datos fueron recolectados por la Dra. Yamileth Solano, catedrática de la Universidad de Costa Rica. La recolección la llevó a cabo a finales de los ochenta como parte de su investigación doctoral sobre los conectores pragmáticos en el habla culta costarricense, bajo la dirección del Dr. Lope Blanch.

2. Las concepciones de modalidad del enunciado y modalidad de la enunciación a que nos atenemos corresponden a las esbozadas por Concepción Otáola (1988) y Halliday (1970).

3. Las nuevas metodologías semántico pragmáticas establecen las diferencias apuntadas partiendo de estos modelos de análisis específicos, pero no dan cuenta de si existe todavía alguna diferencia de carácter sintáctico entre las formas de subjuntivo empleadas como imperativos y las que se usan como meras enunciaciones del deseo del hablante, u optativas .

4. Así lo plantea L. Studerus (1975): "...the so-called "hortatory imperative" is indeed imperative. The only distinguishing feature between it and other imperative usage is that the speaker is to participate in the response" (522), y concuerda con él Moreno de Alba (1978) al afirmar que "...se puede hablar de un imperativo, en sentido lato, de primera persona de plural (nosotros), que viene a ser una especie de exhortativo" ( 125).

5. Debido a que no es de nuestro interés en este momento, no entraremos a discutir problemas de relaciones de dependencia sintáctica y sus repercusiones para el análisis. Evidentemente, las oraciones transpuestas en discurso directo pueden analizarse como subordinaciones del verbo de lengua que las introduce (decir, por lo general); sin embargo, consideramos que en su contexto comunicativo originario estas oraciones fueron independientes y que el hecho de que aparezcan subordinadas ahora es consecuencia de un imposición de las circunstancias comunicativas del momento.

\section{Bibliografía}

Alarcos Llorach, Emilio. 1994. "Estructura del verbo español." Estudios de gramática funcional del español. Tercera edición. Madrid: Gredos, 50-89.

1995. Gramática de la lengua española. Madrid: Espasa Calpe.

Bello, Andrés. 1988. Gramática castellana. Estudio y edición de Ramón Trujillo. Madrid: Arco Libros S.A.

Borrego, J., J.G. Ascencio y E. Prieto. El subjuntivo. Valores y usos. Quinta edición. Madrid: Sociedad General Española de Librería, S.A.

Bosque, Ignacio (comp.). 1990. Indicativo y Subjuntivo. Madrid: Taurus Universitaria.

1990. "Las bases gramaticales de la alternancia modal. Repaso y balance." En: Bosque (comp.), 13-65.

Butt, J. and Benjamin, Carmen. 1994. A new reference grammar of modern spanish. Chicago: NTC Publishing Group. 
Castronovo, Brian J. 1990. "La categoría verbal de modo en la tradición gramatical española." En: Bosque (comp.), 66-8.

Cuestionario para el estudio coordinado de la norma lingüística culta. Morfosintaxis. 1972. Madrid: Concejo Superior de Investigaciones Científicas.

Fernández Ramírez, Salvador. 1986. Gramática española. 4. El verbo y la oración. Editada por Ignacio Bosque. Madrid: Arco Libros S.A.

Flores, Óscar. 1993. "El correlato pragmático de la alternancia indicativo-subjuntivo." Lingüística Española Actual. 15 (1): 65-81.

Gili Gaya, Samuel. 1993. Curso Superior de sintaxis española. Décimoquinta edición. Barcelona: Vox.

Hadlich, Roger L. 1982. Gramática transformativa del español. Madrid: Gredos.

Halliday, M.A.K. 1970. "Functional diversity in language as seen from a consideration of modality and mood in english." Foundations of Language 6 (1970): 322-61.

Hernández Alonso, César. 1995. Nueva sintaxis de la lengua española. Madrid: Ediciones Colegio de España.

Jiménez Julia, Tomas. 1989. "Modalidad, modo verbal y modus clausal en español." Verba: Anuario Galego de Filoloxia. 16 (1989): 175-214.

Kany, Charles. 1969. Sintaxis hispanoamericana. Madrid: Gredos.

Lamíquez, Vidal. 1981. "Sistema verbal y uso del sistema verbal en el habla culta sevillana." Philologica Hispaniensia in honorem Manuel Alvar. Madrid: Gredos, 337-46.

1982. El sistema verbal del español. Málaga: Librería Agora.

1972. Morfosintaxis estructural del verbo español. Sevilla: Publicaciones de la Universidad de Sevilla.

Lope Blanch, Juan M. 1986. El estudio del español hablado culto. Historia de un proyecto. México: UNAM.

Manteca Alonso-Cortés, Ángel. 1981. Gramática del subjuntivo. Madrid: Ediciones Cátedra.

Moreno de Alba, José G. 1978. Valores de las formas verbales en el español de México. México: UNAM. 
Navas Ruiz, Ricardo. 1990. "El subjuntivo castellano. Teoría y bibliografía crítica." En: Bosque (comp.), 107-141.

Otáola Olano, Concepción. 1988. "La modalidad (con especial referencia a la lengua española). Revista de Filología Española. 68 (1-2): 97-117.

Porto Dapena, José Alvaro. 1991. Del indicativo al subjuntivo. Valores y usos de los modos del verbo. Madrid: Arco Libros, S.A.

Real Academia Española. 1973. Esbozo de una nueva gramática de la lengua española. Madrid: Espasa Calpe.

Seco, Rafael. 1988. Manual de gramática española. Madrid: Aguilar.

Solano, Yamileth. (En prensa). El habla culta costarricense. Materiales para su estudio.

Studerus H., Lenard. 1978. "Obliqueness in Spanish imperative utterances." Hispania. 61: 109-117.

1975. "Spanish imperatives and the notion of imperativity." Hispania. 58: 519-23.

Terrel, Tracey. 1994. "Assertion and Presupposition in Spanish Complements." Studies in language learning and Spanish linguistics. In honor of Tracey Terrel. Editado por Hashemipour, P., Maldonado, R. y van Naerssen, M. New York: McGraw-Hill, Inc. 